\title{
Structural and Luminescence Properties of 6-Oxo-5-phenyl-6H-pyrido[3,2,1-jk]carbazol-4-yl thiophene-2-carboxylate
}

\author{
Yong-Kwang Jeong, Min-Ah Kim, Hyo-Sung Lee, Sung Woo Lee, ${ }^{\dagger}$ and Jun-Gill Kang ${ }^{*}$ \\ Department of Chemistry, Chungnam National University, Daejeon 305-764, Korea. ${ }^{*}$ E-mail: jgkang@cnu.ac.kr \\ ${ }^{\dagger}$ Center for Research Facilities, Chungnam National University, Yuseong-gu, Daejeon 305-764, Korea \\ Received March 28, 2014, Accepted June 18, 2014
}

Key Words : Pyridocarbazone, Structure, Luminescence, Proton-substitution effect, Quantum mechanical calculation

Pyrido[3,2,1-jk]carbazol-6-one (PCO) derivatives are very attractive as new materials in organoelectronics and photophysical applications, because of their planar structure with rich $\pi$-electron section. Most studies on PCO derivatives have examined their synthesis and reactions. ${ }^{1-4}$ Previously, we synthesized 4-hydroxy-5-phenyl-6H-pyrido[3,2,1-jk]carbazol-6-one (HPPCO) derivatives and investigated their luminescence properties. ${ }^{5}$ HPPCO exposed to UV light produced deep-blue to green luminescence, depending on the solvent. The solvatochromic effect was strongly associated with the degree of the deprotonation of the hydroxyl group substituted to the fused ring. When the proton of 4-hydorxy was substituted by acetate (6-oxo-5-phenyl- $6 H$-pyrido[3,2,1$j k]$ carbazol-4-yl acetate, OPPCA) or benzoate (6-oxo-5phenyl-6H-pyrido[3,2,1-jk]carbazol-4-yl benzoate, OPPCB), those compounds did not exhibit any solvatochromic effect with the emission peaking at $415 \mathrm{~nm}$. In this study we synthesized 6-oxo-5-phenyl-6H-pyrido [3,2,1-jk] carbazol4-yl thiophene-2-carboxylate (OPPCT), and investigated the structural and luminescence properties as a series of PCO derivatives.

OPPCT crystallized in the monoclinic space group $P 2_{1} / c$ with $a=8.6431$ (11) $\AA, b=35.860(5) \AA, c=6.7100(8) \AA, \beta$ $=111.150(7)^{\circ}, V=1939.6(4) \AA^{3}$, and $Z=4$. Prospective view of OPPCT with the atomic numbering scheme is shown in Figure 1(a), and the geometric parameters are listed in Table S1 (Supporting Information). The PCO fused ring was characterized by the least-squares plane of the $-4.5725(0.0056) \mathrm{x}+0.0103(0.0185) \mathrm{y}+6.5914(0.0013) \mathrm{z}=$ $0.2926(0.0064)$ with a root-mean-square deviation of 0.0481 $\AA$. The average dihedral angle between the main frame and the substituted ring was $60.98(0.13)^{\circ}$ for the phenyl ring and $74.69(0.16)^{\circ}$ for the thiophene ring. There was no classical hydrogen bond resulted from $\mathrm{OH}$ in the three-dimensional arrangements of OPPCT. However, the shortest intermolecular distance between the carbon atom (C19) as a donor (D) and the oxygen atom (O3) of the carbonyl group as an acceptor (A) was $3.360 \AA$, and the next shortest distance, $\mathrm{d}(\mathrm{D} \cdots \mathrm{A})$ was $3.421 \AA$ between $\mathrm{C} 6$ and O1. These D $\cdots \mathrm{A}$ distances are classified as a weak electrostatic interaction. ${ }^{6,7}$ Comparably, the intermolecular hydrogen bond formed by $\mathrm{O} 3$ in the substituted thiophene carboxylate group played a
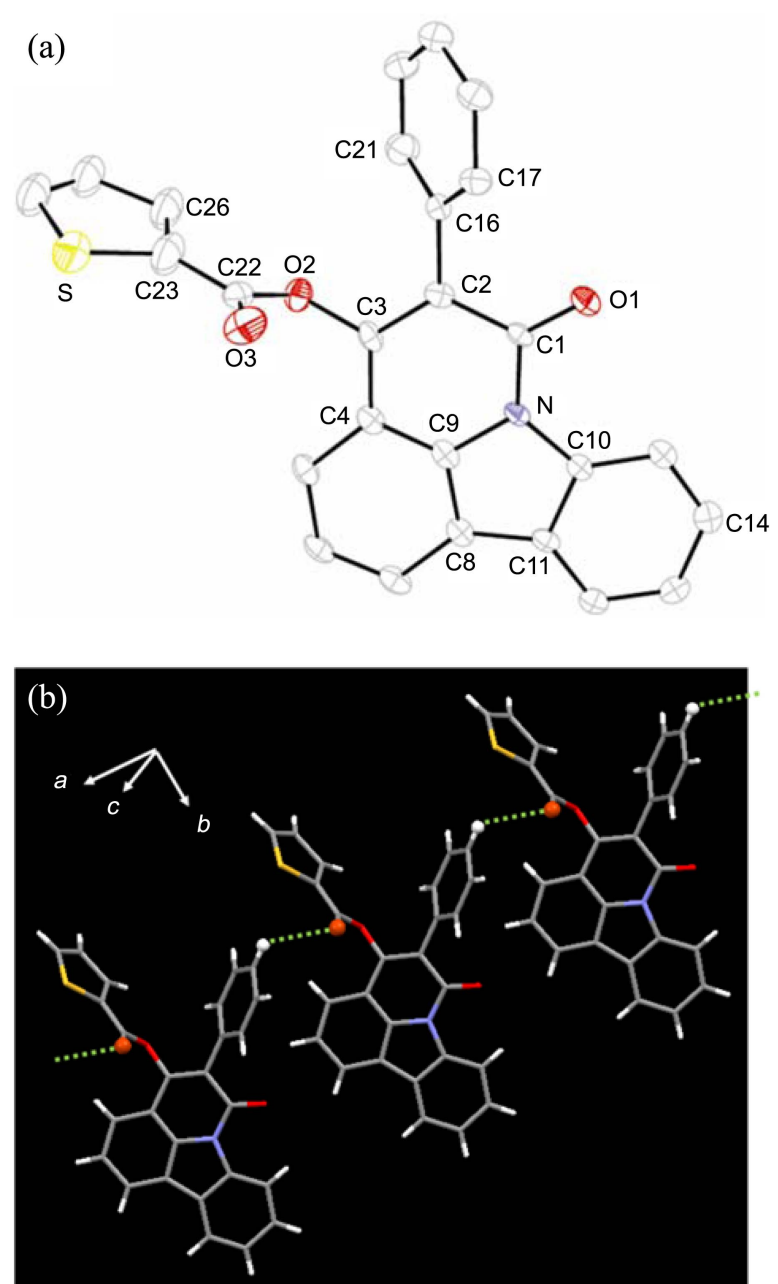

Figure 1. (a) Prospective view of OPPCT showing atomic labeling and ellipsoid at 50\%, and (b) part of the hydrogen-bonded framework of OPPCT.

key role on forming the crystal network, as shown in Figure $1(b)$.

Figure 2 shows the absorption spectra of HPPCO and its derivatives dissolved in dichloromethane (DCM). The absorption spectrum of HPPCO in the $280-450 \mathrm{~nm}$ region consisted of the three A-band components, peaking at 369 , 353 and $339 \mathrm{~nm}$ (these components are referred to as A1, A2 


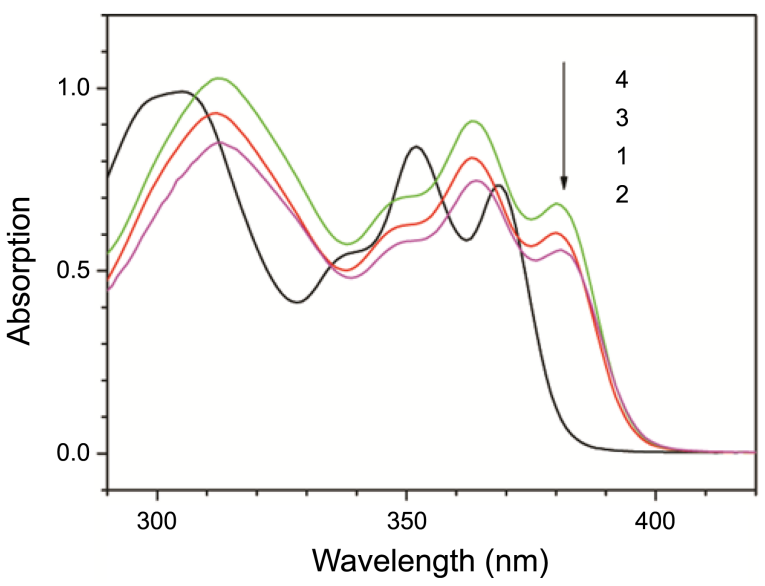

Figure 2. Absorption spectra of HPPCO (1) and its derivatives (2: OPPCT, 3: OPPCA and 4: OPPCB) dissolved in DCM $\left(6 \times 10^{-5} \mathrm{M}\right)$.

and $\mathrm{A} 3$ in order of increasing energy), and the B-band, peaking at $302 \mathrm{~nm}$. There was no significant difference in the intensity and the spectral structure between HPPCO and its derivatives except the redshift by $\sim 10 \mathrm{~nm}$ due to the proton substitution. These results indicated that the A- and Babsorption bands were associated with the electronic transitions of the fused ring. Figure 3 shows the emission and the excitation spectra of HPPCO and OPPCT dissolved in DCM. Taking into account the approximately 10 -nm redshift, the spectral shapes of the emission and the excitation spectra of OPPCT were very similar to those of HPPCO. However, the emission intensity of OPPCT was much stronger than that of HPPCO. The emission spectra of HPPCO and OPPCT resolved into three main components with a low-energy shoulder: 416, 397 and $380 \mathrm{~nm}$ for HPPCO, and 433, 414 and $402 \mathrm{~nm}$ for OPPCT as inserted in Figure 3. The A1, A2 and $\mathrm{A} 3$ excited states were responsible for these three components, respectively. The low-energy shoulder was assigned as the phosphorescence component. The excitation spectrum of the blue emission from OPPCT were also consisted of the three main component (386, 369 and 340 $\mathrm{nm})$ with a high-energy shoulder $(301 \mathrm{~nm})$. The three main

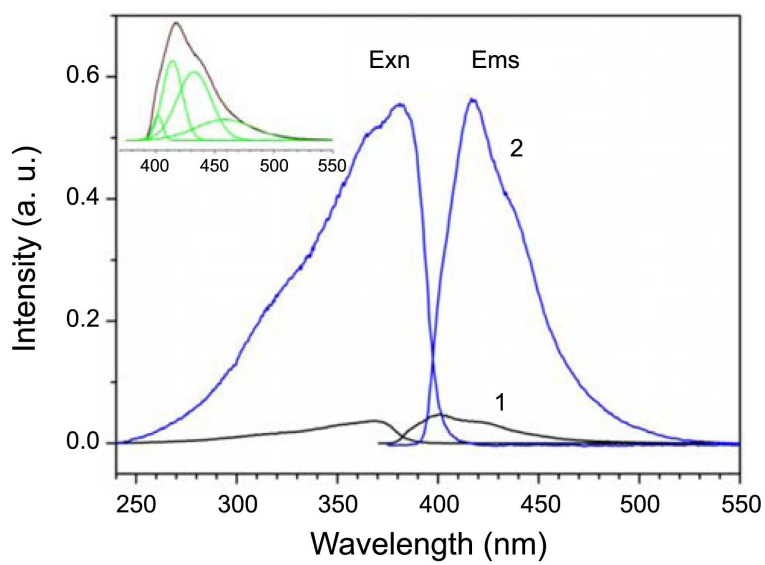

Figure 3. Emission and excitation spectra of HPPCO (1) and OPPCT (2) dissolved in DCM $\left(5 \times 10^{-5} \mathrm{M}\right)$.
Table 1. Luminescence Properties of HPPCO and OPPCT dissolved in DCM

\begin{tabular}{ccccccccc}
\hline & \multicolumn{3}{c}{$\lambda_{\text {ems }} / \mathrm{nm}$} & \multirow{2}{*}{$\Phi / \%$} & $\tau / \mathrm{ns}$ & \multicolumn{2}{c}{$k / 10^{7} \mathrm{~s}^{-1}$} \\
\cline { 2 - 4 } \cline { 7 - 9 } & $\mathrm{A} 1$ & $\mathrm{~A} 2$ & $\mathrm{~A} 3$ & & & $k_{r}$ & $k_{n r}$ \\
\hline HPPCO & 416 & 397 & 380 & 2.7 & 4.2 & 0.64 & 230 \\
OPPCT & 433 & 414 & $402^{a}$ & 14.0 & 5.5 & 2.6 & 160 \\
\hline
\end{tabular}

${ }^{a}$ very weak

components corresponded to the A1 and A2 and A3-absorption bands, respectively; and the high-energy shoulder represented the B-absorption band. The quantum yield and the decay time of the blue luminescence of OPPCT dissolved in DCM were measured, and the results were compared with those of HPPCO in Table 1. The quantum yield of OPPCT $(\Phi=14.0 \%)$ was more than five times as much as that of HPPCO $(\Phi=2.7 \%)$, whereas the observed decay time of OPРCT ( $\tau=5.5 \mathrm{~ns})$ was slightly longer than that of $\operatorname{HPPCO}(\tau=4.2 \mathrm{~ns})$. The quantum yield of the luminescence, defined as the ratio of the number of photons emitted to the number of photons absorbed, also reveals how well the radiative processes compete with non-radiative processes. A general expression for the quantum yield in terms of rate constant is

$$
\Phi=\frac{k_{r}}{k_{r}+k_{n r}}
$$

where $k_{r}$ and $k_{n r}$ are the rate constants for the radiative and the non-radiative processes, respectively. Since $\tau=\left(k_{r}+k_{n r}\right)^{-1}$, the radiative and the non-radiative rate constants are expressed by:

$$
\begin{gathered}
k_{r}=\frac{\Phi}{\tau} \\
k_{n r}=\frac{1-\Phi}{\tau}
\end{gathered}
$$

As listed in Table 1, for OPPCT, the radiative rate-constant was four times as much as that for HPPCO. These results supported that the proton substitution significantly reduced the energy-loss process associated with the $\mathrm{OH}$ group and consequently enhanced the luminescence efficiency.

Theoretical calculations for electronic structures and electronic transitions of OPPCT molecule were also performed to interpret the observed optical properties. The structure was initially optimized using DFT-B3LYP/6-31g(d,p) basis set. ${ }^{8}$ The comparison of geometric parameters determined from the experimental (X-ray) and the optimized structures is given in Table S1 (Supporting Information). The standard deviation between the experimental and the calculated values is $0.0164 \AA$ for the bond lengths and $2.39^{\circ}$ for the bond angles. The large differences were found in the bond angles forming from at least two of $\mathrm{C} 3, \mathrm{O} 2, \mathrm{O} 3, \mathrm{C} 22$ and $\mathrm{C} 23$ atoms. It was due that the crystal packing effect was not accounted in the geometry optimization of the single molecule. Next, a Configuration Interaction Singles (CIS) calculation was performed with ZINDO method ${ }^{8}$ on the basis of 
the optimized geometry. The results for molecular orbitals and electronic structures are listed in Tables S2 and S3, respectively. Comparing the calculated wavelengths with the observed absorption-band positions, the calculated excited states were classified into three groups as listed in Table S3. Among the excited states in group A, the transitions from the $\mathrm{X}$ state to the 1A, 2A and 4A states have moderate oscillator strengths with $f=0.272,0.152$ and 0.235 , respectively, while the $\mathrm{X} \rightarrow 3 \mathrm{~A}$ transitions have lower oscillator-strength with $f$ $=0.012$. The first excited state, $1 \mathrm{~A}$, arose predominantly from the transition from the highest occupied molecular orbital (HOMO), $h 1$, to the lowest unoccupied molecular orbital (LUMO), $l 1$. As shown in Figure 3, the $h 1 \mathrm{HOMO}$ comprised a combination of the $\mathrm{p}_{\mathrm{z}}$ orbitals of carbon atoms in ring $3(\mathrm{C} 4-\mathrm{C} 9)$ and ring $4(\mathrm{Cl}-\mathrm{N})$ of the fused ring, the $\mathrm{p}_{\mathrm{x}}$ and $\mathrm{p}_{\mathrm{y}}$ orbitals of the carbon atoms in the phenyl ring $(\mathrm{ph})$, and the $p_{z}$ orbital of $\mathrm{O} 1$. Note that the molecular axis is represented by the z-axis. The contributions of the fused ring, the phenyl ring and the oxygen atom were $56 \%, 31 \%$ and $9 \%$, respectively. Accordingly, the $h 1 \mathrm{HOMO}$ was characterized as the $\pi$ orbital locating over rings 3 and 4, the oxygen atom of the carbonyl group, and the phenyl ring, hereafter, referred to as $\pi(\mathrm{R} 3,4 ; \mathrm{O} 1 ; \mathrm{ph})$. As shown in Figure 3 , the $l 1$ LUMO was contributed from the $\pi^{*}$ orbital located on ring $2(\mathrm{C} 8-\mathrm{C} 11)$ - ring 4 of the fused ring $(66 \%)$ as main and the $\pi^{*}$ orbital located on the thiophene ring (thio, $18 \%$ ) as minor. These contributions specified the $l 1$ LUMO as $\pi^{*}(\mathrm{R} 2-4$; thio). Accordingly, the A1-absorption component can be assigned as $\pi(\mathrm{R} 3,4 ; \mathrm{O} 1 ; \mathrm{ph}) \rightarrow \pi^{*}(\mathrm{R} 2-4 ;$ thio $)$. The second excited state, $2 \mathrm{~A}$, is predominantly a result of the transitions from the $h 8$ HOMO to the $l 1$ LUMO. The $h 8$ HOMO was contributed from the $\mathrm{p}_{\mathrm{x}}, \mathrm{p}_{\mathrm{y}}$ and $\mathrm{p}_{\mathrm{z}}$ orbitals of O1, of which the contributions were $70 \%, 4 \%$ and $3 \%$, respectively. Thus, the $h 8 \mathrm{HOMO}$ was characterized as $\mathrm{n}(\mathrm{O} 1)$. Another transition, contributed to the $2 \mathrm{~A}$ excited state, was the $h 8 \rightarrow l 4$ transition. The $l 4$ LUMO corresponded to the $\pi^{*}$ orbital locating over rings 3 and $4, \pi^{*}(\mathrm{R} 3,4)$, because their contributions were more than $80 \%$. The $\mathrm{X} \rightarrow 2 \mathrm{~A}$ transition was responsible for the A2-absorption component. The 4A excited state $(f=0.235)$ was resulted from the $h 2 \rightarrow l 1$ transition. The next HOMO, $h 2$, corresponded to $\pi(\mathrm{R} 1-3)$, locating over the carbon atoms in rings 1,2 and $3(>97 \%)$. Accordingly, the $\mathrm{X} \rightarrow 4 \mathrm{~A}$ transition was responsible for the A3-absorption component, assigned as $\pi(\mathrm{R} 1-3) \rightarrow \pi^{*}(\mathrm{R} 2-$ 4 ; thio). The electron density isocontours responsible for the A1, A2 and A3-absorption components are shown in Figure 3.

In summary, when exposed to UV light, HPPCO and its derivative OPPCT produced deep-blue and blue-green luminescence, respectively. The proton substitution increased the luminescence quantum-yield by more than five-fold, due to the reduction of the energy-loss by the hydroxyl group. DFT and ZINDO calculations on the structural and the optical properties showed that the luminescence was strongly associated with the $\pi \rightarrow \pi^{*}$ transitions of the fused ring with a minor contribution coming from the phenyl ring and the oxygen atom of the carbonyl group. The substituted thiophene carboxylate group played a key role on forming the
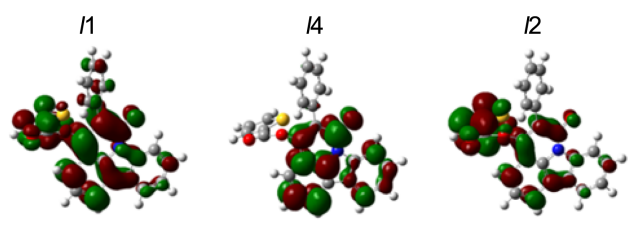

h1

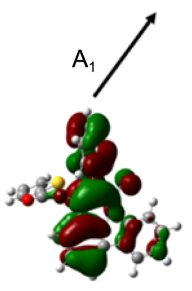

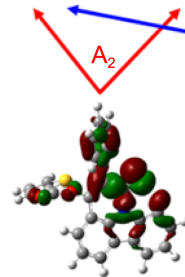

h8

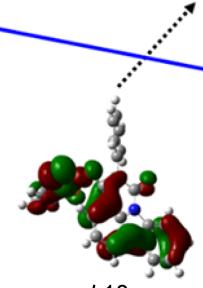

$h 10$
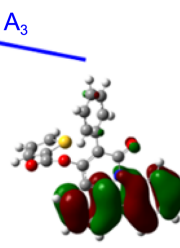

h2
Figure 3. Electron density isocontours of some HOMOs and LUMOs involved in the A-band transitions of OPPCT.

crystal network.

\section{Experimental}

Synthesis of OPPCT. HPPCO was synthesized from carbazole $(8.35 \mathrm{~g}, 0.05 \mathrm{~mol})$ and diethyl phenylmalonate (14.15 g, $0.06 \mathrm{~mol}$ ) according to Method A described in Ref. 1. A mixture of HPPCO (3.1 g, $10 \mathrm{mmol})$ and potassium carbonate $(1.38 \mathrm{~g}, 10 \mathrm{mmol})$ was dissolved in acetone $(300$ $\mathrm{mL})$. To the greenish acetone solution, 2-thiophenecarbonyl chloride (1.61 g, $11 \mathrm{mmol}$ ) was added and stirred at room temperature for $3 \mathrm{~h}$. The orange powder was filtered and then dissolved in a 1:1 chloroform and water mixed solvent (200 mL). The organic phase was separated and dried over anhydrous magnesium sulfate. The precipitate was obtained by evaporating the solvent and then was washed several times with hexane. ${ }^{1} \mathrm{H}$ NMR $\left(\mathrm{CDCl}_{3}\right) \delta 1 \mathrm{H}, \mathrm{d}, 8.73(\mathrm{~J}=8$ $\mathrm{Hz}), 1 \mathrm{H}, \mathrm{d}, 8.16(\mathrm{~J}=8 \mathrm{~Hz}), 1 \mathrm{H}, \mathrm{d}, 8.08(J=8 \mathrm{~Hz}), 1 \mathrm{H}, \mathrm{d}$, $7.87(J=4 \mathrm{~Hz}), 1 \mathrm{H}, \mathrm{d}, 7.68(J=8 \mathrm{~Hz}), 1 \mathrm{H}, \mathrm{d}, 7.66(J=4$ $\mathrm{Hz}), 1 \mathrm{H}, \mathrm{t}, 7.59(\mathrm{~J}=8 \mathrm{~Hz}), 4 \mathrm{H}, \mathrm{m}, 7.55-7.51,1 \mathrm{H}, \mathrm{t}, 7.50(\mathrm{~J}=$ $8 \mathrm{~Hz}), 2 \mathrm{H}, \mathrm{t}, 7.38(\mathrm{~J}=8 \mathrm{~Hz}), 1 \mathrm{H}, \mathrm{t}, 7.31(J=8 \mathrm{~Hz}), 1 \mathrm{H}, \mathrm{d}$, $7.13(\mathrm{~J}=4 \mathrm{~Hz})$. Anal. found: $\mathrm{C}, 72.7 ; \mathrm{H}, 3.3 ; \mathrm{N}, 3.7$; O, 12.2; S, 6.6. Calcd. for $\mathrm{C}_{26} \mathrm{H}_{15} \mathrm{NO}_{3} \mathrm{~S}: \mathrm{C}$, 74.1; H, 3.6; N, 3.3; O, 11.4; S, 7.6.

X-ray Crystallograpy. Single crystals of OPPCT were grown from dichloromethane solution using the slowevaporation method. Diffraction data were collected at room temperature on a Bruker SMART CCD diffractometer using graphite monochromated Mo K $\alpha$ radiation. The structure was solved by applying the direct method using SHELXS97 and refined by a full-matrix least-squares calculation on $F^{2}$ using SHELXL-97. ${ }^{9}$ All non-H atoms were refined with anisotropic displacement parameters. Hydrogen atoms were fixed at ideal geometric positions, and their contributions were included in the structural factor calculations. The crystal data and refinement results are listed in Table S4. Crystallographic data for the structure reported here have been deposited with CCDC (Deposition No. CCDC-993939). These data can be obtained free of charge via http:// www.ccdc.cam.ac.uk/conts/retrieving.html or from CCDC, 12 Union Road, Cambridge CB2 1EZ, UK, E-mail: 
deposit@ccdc.cam.ac.uk.

Optical Measurements. The absorption spectra, the luminescence and the excitation spectra, the luminescence quantum yield, and the luminescence decay time were measured using previously described methods. ${ }^{5}$

Acknowledgments. This research was supported by National Research Foundation (NRF-2012R1A1A2007201).

Supporting Information. Geometric parameters from Xray data and optimized calculation (Table S1), molecular orbitals (Table S2), details of CIS excited states (Table S3), and crystal data and refinement (Table S4) are included in supporting information.

\section{References}

1. Dang, H. V.; Knobloch, B.; Habib, N. S.; Kappe, T.; Stadlbauer, W. J. Heterocyclic Chem. 2005, 42, 85.

2. Dang, H. V.; Stadlbauer, W. J. Heterocyclic Chem. 2006, 43, 65.

3. Shivachev, B.; Petrov, P.; Stoyanova, M. J. Chem. Crystallogr. 2009, 39, 209.

4. Stadlbauer, W.; Dang, H. V.; Knobloch, B. W. J. Heterocyclic
Chem. 2011, 48, 1039.

5. Lee, H.-S.; Kim, H.-J.; Kang, J.-G. Photochem. Photobio. Sci. 2011, 10, 1338.

6. Jeffrey, G. A. An Introduction to Hydrogen Bonding; Oxford University Press: New York, 1997; Chapters 2 and 5.

7. Steiner, T; Saenger, W. J. Am. Chem. Soc. 1992, 114, 10146.

8. Frisch, M. J. T.; Trucks, G. W.; Schlegel, H. B.; Scuseria, G. E.; Robb, M. A.; Cheeseman, J. R.; Scalmani, G.; Barone, V.; Mennucci, B.; Petersson, G. A.; Nakatsuji, H.; Caricato, M.; Li, X.; Hratchian, H. P.; Izmaylov, A. F.; Bloino, J.; Zheng, G.; Sonnenberg, J. L.; Hada, M.; Ehara, M.; Toyota, K.; Fukuda, R.; Hasegawa, J.; Ishida, M.; Nakajima, T.; Honda, Y.; Kitao, O.; Nakai, H.; Vreven, T.; Montgomery, J. A., Jr.; Peralta, J. E.; Ogliaro, F.; Bearpark, M.; Heyd, J. J.; Brothers, E.; Kudin, K. N.; Staroverov, V. N.; Kobayashi, R.; Normand, J.; Raghavachari, K.; Rendell, A.; Burant, J. C.; Iyengar, S. S.; Tomasi, J.; Cossi, M.; Rega, N.; Millam, N. J.; Klene, M.; Knox, J. E.; Cross, J. B.; Bakken, V.; Adamo, C.; Jaramillo, J.; Gomperts, R.; Stratmann, R. E.; Yazyev, O.; Austin, A. J.; Cammi, R.; Pomelli, C.; Ochterski, J. W.; Martin, R. L.; Morokuma, K.; Zakrzewski, V. G.; Voth, G. A.; Salvador, P.; Dannenberg, J. J.; Dapprich, S.; Daniels, A. D.; Farkas, Ö.; Foresman, J. B.; Ortiz, J. V.; Cioslowski, J.; Fox, D. J. Gaussian 09 (Revision A. 02); Gaussian, Inc., Wallingford CT, 2009.

9. Sheldrick, G. M. Acta Crystallogr. A 2008, 64, 112. 